\title{
Kernos
}

Revue internationale et pluridisciplinaire de religion grecque antique

12| 1999

Varia

\section{Les Anthestéries et le vin}

\section{Daniel Noel}

Édition électronique

DOI : $10.4000 /$ kernos.715

ISSN : 2034-7871

\section{Éditeur}

Centre international d'étude de la religion grecque antique

\section{Édition imprimée}

Date de publication : 1 janvier 1999

Pagination : 125-152

ISSN : 0776-3824

Référence électronique

Daniel Noel, « Les Anthestéries et le vin », Kernos [En ligne], 12 | 1999, mis en ligne le 13 avril 2011, consulté le 01 mai 2019. URL : http://journals.openedition.org/kernos/715; DOI : 10.4000/kernos.715 
Kernos, 12 (1999), p. 125-152.

\section{Les Anthestéries et le vin}

La plus importante fête du vin dionysiaque, les Anthestéries, se célébrait en février-mars, du 11 au 13 Anthestérion. Le premier jour s'appelait Pithoigia, "ouverture des jarres ». Une libation à Dionysos précédait la dégustation du vin nouveau. Le deuxième jour, Cboes ou "Conges », se déroulait le concours des Choes qui consistait à vider le plus vite possible, au son de la trompette, un chous. Cela se faisait en souvenir de l'hospitalité accordée à Oreste par les Athéniens. Le même jour se déroulait une autre cérémonie, le mariage sacré de la femme de l'archonte-roi, la Basilinna, avec Dionysos. Le dernier jour, Cbytroi, « Marmites », était consacré aux morts. Dans des marmites, on offrait à Hermès chthonien une panspermie et le soir on congédiait les âmes des morts avec la formule : « À la porte, les Kères; finies les Anthestéries ».

Ces fêtes sont les seules qui concernent à proprement parler le vin et les pratiques qui lui sont attachées. Athènes n'a pas connu de fêtes de la vigne ou de la taille qui facilite la fructification, pas davantage de fête des vendanges. Aux Anthestéries, les manifestations en rapport direct avec le vin occupent au cours des trois journées une place décroissante, lors de la dernière journée il n'est plus du tout question du vin et de son dieu.

Des quatre fêtes athéniennes de Dionysos, la plus prisée des savants est celle des Anthestéries. L.R. Farnell, après l'étude des Lénéennes, affirme que celle des Anthestéries est plus importante pour l'étude des questions religieuses $^{1}$. P. Foucart, à la même époque, défend un même point de vue et remonte aux sources de la religion grecque, dans la vallée du Nil ${ }^{2}$. Dès la fin du $\mathrm{XIx}^{\mathrm{e}}$ siècle, pour E. Rohde, à Athènes, « la principale fềte de toutes les âmes tombait au printemps, à la fête dionysiaque des Anthestéries... C'était le temps où les morts revenaient dans le royaume des vivants $»^{3}$. J. Harrison fait des Anthestéries une fête des âmes des morts. Après avoir relevé qu'une certaine tristesse parcourt les Anthestéries ${ }^{4}$, elle s'empare de la formule: «Dehors les Kères, les Anthestéries sont finies » pour en faire la clé de voûte

\footnotetext{
1. L.R. FarnelL, Cults of the Greek States, V, Oxford, 1909, p. 214.

2 P. Foucart, Le culte de Dionysos en Attique, Paris, 1904, p. 159.

3 E. Rohde, Psyché. Le culte de l'âme chez les Grecs et leur croyance en l'immortalité, Paris, 1928 [or. all. 1891], p. 195.

4 J.E. Harrison, Prolegomena to the Study of Greek Religion, Cambridge, 1903, p. $32-$
} 
de son interprétation ${ }^{5}$. Elle mobilise ce que la fête contient d'indices " chthoniens ", de jours néfastes et d'âmes des morts voletant autour d'un pitbos $^{6}$. Plus tard, elle revient sur le sujet. Là où elle voyait deux strates superposées elle n'en voit plus qu'une combinant les âmes et la fertilité $e^{7}$. Les Anthesteries deviennent « a feast of revocation of souls and the blossoming of plants, a feast of the great reincarnation cycle of man and nature $»^{8}$. M.P. Nilsson conservera la dualité des fêtes au sein des Anthestéries, le monde souterrain et la fertilité, solidaires et constitutifs de Dionysos.

Un peu plus tard, W. Otto se détourne résolument d'une telle attitude et salue en $\mathrm{E}$. Rohde le découvreur du royaume des morts, une province de l'empire de Dionysos 9 . Surtout il bataillera ferme contre ceux qui, comme Nilsson ou Deubner, s'interrogent pour savoir si Dionysos, qui n'est qu'un dieu de la fertilité, n'aurait pas investi une fête des morts plus ancienne. Il invoque l'autorité d'Héraclite à l'appui de sa thèse ${ }^{10}$, La réponse est catégorique : «qui tient cette association (Hadès-Dionysos), en dépit de sa haute antiquité, pour plus ou moins artificielle ne peut se réclamer que d'une idée préconçue de l'essence et de l'origine de Dionysos " ${ }^{11}$. Dans l'histoire de Dionysos, W. Otto occupe une place importante parce qu'il dépasse le dualisme fertilité / monde souterrain en dénonçant le naturalisme qui domine les explications des mythes des dieux qui meurent et qui renaissent et que, de plus, il s'oppose à la conception triviale de la mort comme « une vie au passé ». Il synthétise sa conception de Dionysos dans une formule très ramassée: “Dionysos est les deux à la fois, Vie et Mort, car son esprit se manifeste à partir des abîmes où vie et mort se nouent et s'entrecroisent ${ }^{12}$. W. Otto a déjà écrit que « dans la religion chthonienne, le mort ne se sépare pas de la communauté des vivants. Il n'en est devenu que plus puissant et plus respectable... Certains jours, quand la terre s'attendrit et que point une vie neuve, tous les morts reviennent et sont accueillis dans la fête jusqu'à ce que s'achève le temps de leur visite ${ }^{13}$. Les Anthestéries constituent un mo-

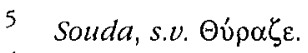

6 « The Anthesteria was a festival of ghosts, overlaid by a festival of Dionysos, and so far the riddance of ghosts by means of placation has been shown to be an important element in ancient sacrifice and in the ancient notion of purification 》(HARrison, Prolegomena [n. 4], p. 76).

7 J.E. Harrison, Themis. A Study of the Social Origines of Greek Religion, Cambridge, 1912 , p. $275-294$

8 Ibid., p. 294.

9 W. Oтro, Les dieux de la Grèce, Paris, 1981 [or. all. 1929], p. 30-31.

10 w. Oтто, Dionysos, le mythe et le culte, Paris, 1969 [or. all. 1933], p. 122-127; HérACLITE, fr. 14 D.-K

11 Ibid, p. 125.

12 Ibid, p. 198-199.

13 Oтro, Les dieux de la Grèce (n. 9), p. 46. 
ment privilégié où se dégage la co-naturalité des hommes et de Dionysos. Les hommes ressentent la présence du dieu, une présence immédiate ${ }^{14}$.

H. Jeanmaire, lui aussi, était persuadé de l'union intime des aspects contradictoires de Dionysos ${ }^{15}$. Mais selon L. Gernet, H. Jeanmaire a montré que Dionysos est devenu dieu de la vigne en raison d'« une place à prendre » car « l'expansion de la vigne s'était faite sans patronage religieux bien défini ${ }^{16}$. Ensuite il confirme ses propres thèses : « le moment de l'année où se situent les festivités dionysiaques est celui d'une vie populaire intense où les frairies apportent le réconfort et la joie; mais traditionnellement aussi c'est celui où se produit le contact avec le monde de l'au-delà... les Anthestéries en particulier témoignent de cette richesse de sentiments $\gg{ }^{17}$.

Ce n'est qu'avec W. Burkert que les Anthestéries deviennent une fête « which is very directly concerned with wine-drinking ${ }^{18}$. Pendant la dernière journée de la fête, Hermès Chthonios reçoit un sacrifice qui s'explique par « the hypothesis of a secondary combination ${ }^{19}$. La cité des vivants est saisie mais l'existence même et ses repères sont bouleversés ${ }^{20}$. La fête n'est plus tiraillée entre fertilité et monde souterrain. W. Burkert repousse les interprétations soucieuses de retrouver les archétypes et les questions éternelles de l'esprit humain. L'ouverture des jarres donne aux Anthestéries leur signification générale. De plus, Burkert possède une solide théorie du sacrifice. Selon lui, les pratiques sacrificielles et les pratiques funéraires sont deux ordres de pratiques présentant une identité de structure et de fonction ${ }^{21}$. À partir de là, il développe une vision où des aspects rituels hétérogènes peuvent être interprétés comme participant à la succession de dissolutions, destructions et de "ré-institutions » de l'ordre de la vie ${ }^{22}$. Burkert congédie et les âmes et le flot d'interprétations qui en découlent ${ }^{23}$. Aucun caractère infernal ne subsiste dans son interprétation et la journée des Cbytroi en est comme nettoyée, la panspermie devenant le signe d'un végétarisme quand, au même moment, les Olympiens et la nourriture crue sont écartés du rituel. Et Hermès Psychopompe? juste un intermédiaire entre la terre et l'au-delà

14 M. Detienne, Préface, in Otto, Les dieux de la Grèce (n. 9), p. 15-19.

15 H. Jeanmaire, Dionysos, Histoire du culte de Baccbus, Paris, 1951, p. 55.

16 L. Gernet, Dionysos et la religion dionysiaque : éléments bérités et traits originaux, in $R E G, 66$ (1953), p. 377-395, repris dans Antbropologie de la Grèce antique, Paris, 1976, p. 65 .

17 Ibid.

18 W. BuRkert, Greek Religion, Oxford, 1990 [or, all. 1977], p. 163.

19 Ibid, p. 217.

20 Ibid., p. 241.

21 W. BURKert, Homo Necans. Antropologia del sacrificio cmento nelle Grecia antica, Turin, 1981 [or. all. 1972], p. 52-72.

22 Ibid., p. 162-163.

23 Ibid., p. 167 
qui conduit et ramène Dionysos. Burkert est déterminé à éradiquer des Anthestéries la combinaison fertilité-monde souterrain qui domine l'interprétation depuis un siècle, et c'est, davantage que cette manière de voir derrière chaque rituel l'écho de la pratique sacrificielle, le principal apport de sa réflexion.

Après Burkert, il devient possible de retravailler à l'interprétation des Anthestéries, débarrassée du naturalisme et du souterrain, et de ressaisir la fête en rapport avec le vin. Pourtant, ce n'est guère ce qui s'est produit ${ }^{24}$. Ainsi M. Daraki se montre une fidèle héritière de Jane Harrison même si elle rectifie des thèses de sa prestigieuse devancière. Aux Anthestéries, les âmes des morts opèrent une « sortie collective » des pithoi qui ne sont pas des tombes mais bien des vases à vin, et le jour de la Pithoigia « coïncide avec l'ouverture du monde infernal ${ }^{25}$. La même perspective mystique conduit M. Daraki à voir dans le mariage sacré le moment culminant de la fête ${ }^{26}$, à faire du "dionysisme " une protestation contre la raison ${ }^{27}$. Les Infernaux envahissent la cité et se mêlent aux vivants. Chacun devient « enfant de la terre », un grand retour dans le tout originel ${ }^{28}$. Il ne suffit pas de crier au loup pour s'en protéger, M. Daraki en témoigne par son évocation du « mystérieux Dionysos qui "est là" et qui menace constamment son historien de conversion " ${ }^{29}$. À l'opposé, H. W. Parke constate, après une présentation sobre des matériaux des Anthestéries, une «curious mixture of ceremonies » ${ }^{30}$. Prudemment, là où les érudits cherchent à montrer Dionysos relié à la mort, à

24 J.A. Dabbab-Trabulsi, Dionysisme, pouvoir et société, Besançon-Paris, 1990. Dans ce travail récent et « historique » sur Dionysos, l'auteur fait confiance à Jeanmaire et à son Dionysos, à la fois " dieu du renouveau printanier et émissaire du monde souterrain ». En « historien », J.A. Dabbab-Trabulsi ne manque pas de noter que, sur l'autre rive de la mer Égée, les Anthestéries ne présentent qu'un caractère joyeux. Il suppute alors que l'aspect néfaste a dû être ajouté à Athènes après la migration (p. 209).

25 M. Daraki, Dionysos, Paris, 1985, p. 39-40. Les vases des Lénéennes serviront de témoignage de la fête des Lénéennes et de la Pitboigta. M. Daraki produit une étrange interprétation du stamnos de Naples : «Figure de l'au-delà, Dionysos-pilier au masque fait cö̈ncider son épiphanie avec trois ouvertures du monde des morts; celle des lénoi, celle des pitbol, celle du temple de limnai», cette lecture étant rendue possible parce que, quelques lignes plus haut, l'auteur voyait sur « les vases, Dionysos-pilier, porteur du masque présider à des rituels qui consistent essentiellement à transvaser le contenu des pitboi déposés devant lui »; Ibid., p. 24. Il s'agit en réalité de vases appelés conventionnellement stamnoi qui ne peuvent se confondre avec des pitboi, sauf à être transporté par une vision. Il faut peut-être davantage incriminer M.P. Nilsson que Dionysos de l'erreur de M. Daraki. Pour ce savant, les vases des Lénéennes étaient en réalité ceux des Anthestéries; M.P. Nilsson, Die prozessionstypen im griechischen Kult, in JdAI, 31 (1916), p. 329.

26

27

28

29

30 H.W. PARke, Festivals of the Atbenians, Londres, 1977, p. 119.
DARAKI, op. cit. (n. 25), p. 114.

Ibid., p. 235.

Ibid., p. 236.

Ibid., p. 235. 
Hermès Chthonien et sa bouillie de graines, il préfère supposer « that the conjunction of the festivals was originally accidental, but that in the course of a long period they became to some extent interpenetrated ${ }^{31}$. Les choses sont compliquées, $\mathrm{H}$.W. Parke le sait bien et il convoque l'Athénien «moyen » pour lui faire dire qu'il ne devait pas comprendre grand-chose à toutes ces histoires. En revanche, il est sûr que, pour son Athénien, la fête « must have felt like Hallow-e'en- an occasion mainly for jolly parties with perhaps at times a somewhat feerie atmosphere to it and certain odd traditional games all which simply added spice to the occasion ${ }^{32}$. Dans sa récente étude sur les Anthestéries, R. Hamilton est prisonnier d'un scepticisme académique ${ }^{33}$. L'auteur résume la fête par un emprunt à W. Burkert ${ }^{34}$ et explique que la moitié des activités des Anthestéries décrites par Burkert sont fermement attestées. Quant au reste... R. Hamilton reste le plus souvent en deçà de ses sources, esquivant le travail d'interprétation ${ }^{35}$.

Les études sur les Anthestéries ont oscillé entre deux extrêmes. D'un côté, un mysticisme découlant d'une philosophie de la nature humaine et de ses éternels soucis; de l'autre, un inventaire des sources toujours à remettre en ordre pour dégager une signification triviale ou pas de signification du tout. Seul W. Burkert opère une véritable échappée. Après lui, il est possible de revisiter les Anthestéries avec un autre regard, à distance des écueils repérés et en prenant la même base de départ que lui, - les Anthestéries se rapportent étroitement au vin de Dionysos, - mais sans s'égarer du côté de la religion primitive et du sacrifice comme matrice explicative systématique ${ }^{36}$. Ainsi le rapport entre le vin de Dionysos et les Anthestéries demeure à établir.

\section{La Pithoigia}

« À Athènes, ils commencent les cérémonies du vin nouveau le 11 du mois d'Anthestèrion, et ils appellent ce jour Pithoigia, » écrit Plutarque dans ses Propos de table $e^{37}$, et « il paraît que jadis, offrant des libations de ce vin avant d'en boire, ils priaient que l'emploi de ce breuvage devienne pour eux inoffensif et salutaire ${ }^{38}$. La date de la célébration de la fête se rapporte au processus même de la vinification : «après le passage du zéphyr, car aucun

31 Ibid.. Sur les rapports de Dionysos et d'Hermès dans la céramique attique, voir

E. Paribeni, Hermes e Dioniso, Scritti di Enrico Paribeni, Rome, 1985, p. 77-80.

32 Ibid., p. 119-120.

33 R.H. Hamilton, Choes and Antbesteria, Atbenian Iconograpby and Ritual, Ann Arbor, 1992.

34 Ibid., p. 2-3.

35 Ibid., p. 60-62.

36 Burkert, Greek Religion (n. 18), p. 163; Homo Necans (n. 21), p. 52-72.

37 Plut., Propos de Table, III, 7, 1 (Mor., 655e).

38 Ibid. 
vent n'altère et ne fait tourner le vin autant que celui-ci, et l'on considère que le vin qui a résisté à son influence se conserve ensuite intact ${ }^{39}$. »

Dans le courant de février, le vin s'est remis à travailler. L'association du zéphyr et du vin, chez Plutarque, exprime que le vin est à nouveau saisi de frémissement, dans la mesure où les Anciens ignoraient les mécanismes biochimiques de la fermentation. Si le vin surmonte cette épreuve, il est assuré de demeurer stable. Plutarque livre une vision claire du vin au moyen de deux verbes :

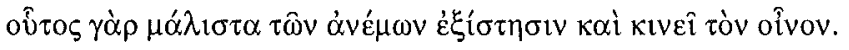

Car aucun vent n'altère et ne fait tourner autant le vin que celui- $\mathrm{ci}^{40}$.

Les verbes $\dot{\varepsilon} \xi \dot{\imath} \sigma \tau \eta \mu$ et $\kappa ı v \varepsilon ́ \omega$ ne signifient pas explicitement la fermentation mais le mouvement. Le vin dans sa période de vinification est animé comme une personne, il vit. Plus que le mouvement, é $\xi \hat{\imath} \sigma \tau \eta \mu \iota$ correspond à un état d'agitation important associé à un changement de nature, à une sortie de soi. Après le passage du Zéphyr, le vin cesse de s'agiter, il connaît un nouvel état, la plus grande stabilité. Le vin est apte à se mouvoir vivement dans les pitbol, sujet d'émerveillement. Un dieu habite le vin, un dieu est le vin et tant qu'il est agité, il demeure intouché. Une fois l'étape biochimique de la vinification terminée et le vin biologiquement stable ${ }^{41}$, l'approche du vin se fera prudemment, le contact avec Dionysos étant toujours un événement im-

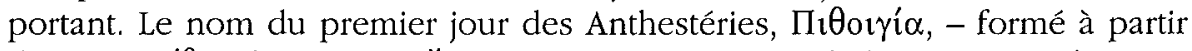
des mots $\pi i \theta_{o}$, la jarre, et oli $v v \mu l$, ouvrir - témoigne de l'importance du geste de l'ouverture des jarres. Ouvrir les jarres marquait la fermeture de la parenthèse commencée avec la vendange et achevée avec la précipitation des dernières lies. Il serait abusif d'imaginer que le vin, une fois les pitbo $i$ ouverts, en avait terminé avec Dionysos et qu'un rite de remerciement envers le dieu et sa générosité suffisait à donner au breuvage une valeur profane. À aucun moment de son histoire en Grèce, le vin n'est un breuvage laïcisé mais il reste dans la sphère du dieu. D'où la nécessité d'accorder de l'intérêt à l'antique équation Dionysos $=\operatorname{vin}^{42}$.

Une fois les jarres ouvertes, les Athéniens rendent hommage à Dionysos par des libations. Selon Plutarque, les Athéniens prient que le vin leur soit non seulement inoffensif mais encore salutaire. Cette prière indique les inquiétudes que le vin suscite. Avant d'être un breuvage, une boisson, c'est un $\varphi \alpha ́ \rho \mu \alpha \kappa o v$, un produit ambigu qui procure un bienfait ou perd celui qui le consomme; le vin peut réjouir ou empoisonner. Il faut s'adresser à Dionysos, au vin lui-même pour ne pas se les aliéner et risquer de voir la source de plai-

\footnotetext{
39 Ibid. (trad. Fr. Furhmann, Paris, $1972[C U F])$.

40 Ibid.

41 R. Cordonnier, La biochimie du vin, in Pour la Science, 36 (1980), p. 50-64.

42 Eur., Cycl, 525 (trad. L. Méridier, Paris, 1976 [CUF]); Ipb. en T., 953 (trad. H. Grégoire, L. Parmentier, Paris, 1925 [CUF]).
} 
sirs devenir un poison mortel. Plutarque n'informe pas sur les détails du déroulement de la Pitboigia mais donne la possibilité de restituer une part de l'imaginaire du vin. Pour ce qui est du déroulement de la Pitboigia, seul un fragment de l'atthidographe Phanodème subsiste :

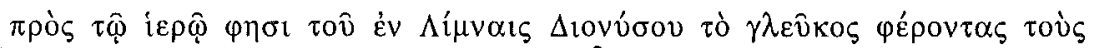

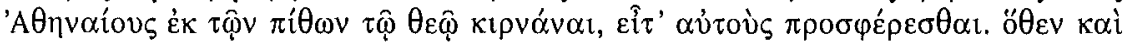

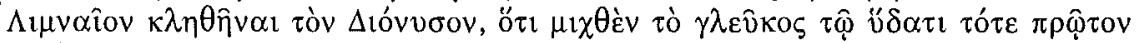

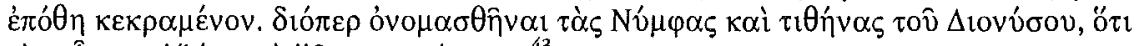

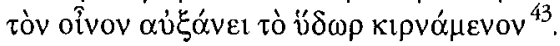

Au sanctuaire de Dionysos du Marais, les Athéniens apportaient le vin doux des jarres et en mélangeaient pour le dieu et ensuite en prenaient pour eux-mêmes. C'est pour cela que Dionysos était appelé dieu du Marais, parce que le vin doux était mélangé et bu avec de l'eau à cette occasion pour la première fois. C'est pourquoi les Nymphes étaient appelées aussi les nourrices de Dionysos parce que l'eau augmente le vin quand il est mélangé avec elle.

Comment les Athéniens pouvaient-ils mélanger le vin pour Dionysos et pour eux-mêmes dans le sanctuaire du Marais quand celui-ci n'est ouvert qu'un jour par an, le douze du mois d'Anthestèrion ${ }^{44}$ ? Faut-il corriger le texte comme Jacoby et lire $\pi \rho$ ò $\varsigma$ iò ípóv, de façon à comprendre «vers le sanctuaire », ce qui laisse la question ouverte ${ }^{45}$, ou ne pas corriger le texte et comprendre comme Deubner «au voisinage du sanctuaire ${ }^{46}$ ? Ou suivre Burkert qui propose une rétrospective de cette journée et la résolution de l'épineux problème philologique, le tout dans une atmosphère de carnaval ${ }^{47}$ ? Les incertitudes sont nombreuses : à l'intérieur ou à l'extérieur du Limnaion, le 11 ou le 12 au petit matin, après une longue journée de voyage et une nuit d'excitation, avec un échantillon ou de lourdes jarres. Phanodème ne livre pas moins d'importants renseignements qui se combinent avec ceux de Plutarque. Plutarque rapporte que les Athéniens priaient pour que le vin soit inoffensif et salutaire pour eux. Phanodème indique comment: par le mélange.

Les Athéniens préparent pour le dieu et pour eux-mêmes un vin mélangé d'eau. Dionysos a enseigné aux hommes l'art du mélange, mais le contexte ne renvoie pas explicitement à la législation d'Amphictyon orientée vers le symposion qui, selon Philochore, prévoit de boire un peu de vin pur pour éprou-

45 F. JACOBY, FGrHist, III b, Suppl., Leyde, 1954, p. 185 sq.

46 L. Deubner, Attische Feste, Berlin, 1932, p. 127 sq.

47 BurKert, Homo Necans (n. 21), p. 160-161. 
ver la puissance du dieu avant de le boire mélangé et à volonté ${ }^{48}$. À en croire Phanodème, le passage du vin pur du pithos au vin mélangé s'opère sans transition; la désacralisation se manifeste avec le coupage qui place le vin consommé ce jour à distance de celui qui s'agitait peu de temps avant la fête dans les jarres. À Dionysos est donc adressé un vin mélangé. Le vin du dieu et le vin des hommes sont identiques et par là s'opère un important rapprochement entre le dieu et les participants à la Pithoigia avec le partage du même vin. Phanodème donne une explication rationalisante, sur un plan non pas concret mais symbolique. S'il avait voulu dire qu'en ajoutant de l'eau au vin il en résultait un volume supérieur, le bon sens lui suffisait et lui épargnait le recours à un parallèle entre Dionysos-Nymphes et vin-eau.

Les Nymphes sont dites les nourrices de Dionysos parce qu'elles élevèrent Dionysos sur le Mont Nysa ${ }^{49}$. Grâce à leur action protectrice et aux soins dont elles entourèrent sa croissance dans un environnement végétal et humide, il fut sauvé, il grandit et devint un homme aux traits d'adolescent ${ }^{50}$. D'une façon homologue, l'eau favorise le développement du vin et le conduit à son achèvement, un liquide bienveillant pour les hommes. Le vin mélangé atteint avec l'eau, comme Dionysos avec les Nymphes, une sorte de complétude, de maturité, et il est équivalent à Dionysos. Vivant, le vin connaît un processus de croissance avec l'eau, de la même manière que Dionysos, après sa conception et sa naissance tumultueuses, avait connu une phase de croissance dans les grottes des Nymphes. L'un et l'autre, afin de poursuivre une carrière parmi les mortels, durent recourir au service soit des Nymphes soit de l'eau, entités équivalentes. Dionysos devenu adulte a conservé les traits de l'âge antérieur. Le vin coupé d'eau conserve aussi des traits d'un état antérieur, celui de l'état pur. Le vin mélangé n'est pas seulement du vin, c'est toujours Dionysos ${ }^{51}$.

Le vin ne sort pas de l'univers dionysiaque avec le mélange, ce sont les buveurs qui y entrent. Ils se rapprochent de Dionysos et le vin devient salutaire. Par le mélange, les Athéniens rencontrent Dionysos, via les Nymphes et l'eau ${ }^{52}$. Le rite de la Pithoigia projette le vin, après l'isolement de la vinifica-

48 Phlloch., FGrHist, 328 F 5b Jacoby = AthénÉe, I, 38c (trad. A.M. Desrousseaux avec le concours de Ch. Astruc, Paris, 1956 [CUF]).

49 Hymne bom. à Dionysos II, 1-10; Diod. Sic., III, 70; Hygin, Fab., 183.

50 Hymne bom. à Dionysos, I, 3.

51 P. VILlARD, Recherches sur l'iuresse dans le monde grec, Thèse de doctorat d'État, Aix-en-Provence, 1988, p. 339.

52 Le lien entre l'eau et le vin est développé sur une amphore du peintre de Priam. Sur une face, Dionysos, assis sur un siège pliant, tient un canthare, entouré d'une puissante treille dans laquelle sept Satyres vendangent; sur le sol, sont déposées trois corbeilles pleines de grappes de raisin. Sur l'autre face, sept femmes nues se livrent au plaisir de l'eau, du bain et de la toilette autour d'une fontaine. Les scènes se prêtent mal à une identification réaliste. L'eau en abondance ordonne un paysage bucolique, presque magique. Une série de correspondances relie les deux faces du vase. Un même nombre de personnages s'active de chaque côté, les uns dans l'eau, les autres dans la vigne. L'eau 
tion, dans la sphère publique de la consommation. Une scholie de Tzetzès à Hésiode livre une information capitale :

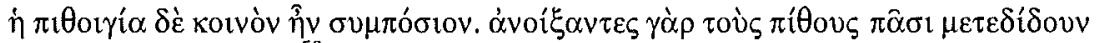

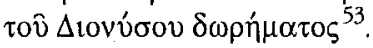

La Pithoigia était un symposion public. Ayant ouvert les pithoi, on donnait à tous une part du don de Dionysos.

Un symposion public se tenait à Athènes le jour de la Pitboigia ${ }^{54}$. La communauté était réunie. Ce moment est désigné par un terme spécifique, $\sigma v \mu \pi o ́ \sigma t o v$, qui le distingue comme un rituel spécifique et séparé du banquet sacré qui suit ordinairement le sacrifice. Une autre scholie à ce passage d'Hésiode ajoute une donnée complémentaire :

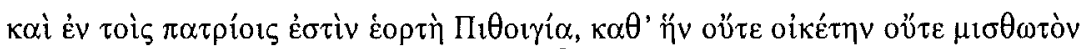

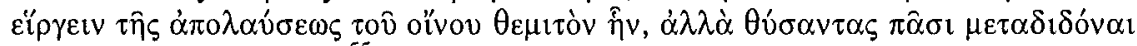

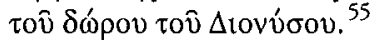

Et parmi les traditions ancestrales, il y a une fête Pithoigia au cours de laquelle il n'était pas permis de garder un esclave ou un salarié à l'écart de la joie du vin, mais où, après avoir sacrifié, il fallait donner à tous une part du don de Dionysos.

Le scholiaste mentionne un sacrifice et une distribution de vin. Il n'est question ni de symposion ni de caractère public. Dans ce témoignage, les destinataires du don de Dionysos ne sont réunis ni par un rite communautaire, le «boire-ensemble », ni par une spécification attestant du caractère politique du rite. Les rites évoqués dans cette scholie sont distincts de ceux de la précédente, ouverture des pithoi et symposion public. Ici, après le sacrifice, le don de Dionysos s'adresse non à des « groupes fonctionnels » mais à la cité en tant que communauté englobant et transcendant ces groupes. La distribution du vin s'adresse à tous, sans restriction liée au statut dans la cité et sans que soit spécifiée la modalité de la consommation de ce vin, comme

irrigue une scène et le vin pur l'autre scène. La scène féminine, et abondante en eau, rencontre la scène masculine, et dominée par le vin pur. Dionysos et son vin sont ici représentés dans leur solidarité et avec les femmes et avec l'eau. Ainsi que l'exprimait Phanodème, cette association vise une, heureuse consommation du vin. Elle est supposée par le vase sur lequel les deux scènes sont peintes, une amphore qui sert au transport du vin du symposion; Rome, Villa Giulia 2609, amphore AFN; $A R V^{2}, 146 / 8$ ter. W.G. Moon, The Priam Painter: some Iconograpbic and Stylistic Considerations, in W.G. Moon (éd.), Ancient Greek Art and Iconography, Madison, 1983, p. 110.

53 Tzétzès, scholie à Hésiode, Les travaux et les jours, 368 Gaisford (Leipzig, 1823).

54 Hamilton, op. cit. (n. 33), p. 8; voir en particulier : O. Murray, La legge soloniana sulla bybris, in AION (1987), p. 121; Fr. Lissarrague, Un flot d'images. Une esthétique du banquet grec, Paris, 1987, p. 92; P. Schmitr, La cité au banquet. Histoire des repas publics dans les cités grecques, Paris, 1992, p. 27, 480.

55 Scholie ancienne à Hésiode, Les travaux et les jours, 368 Pertusi (Milan, 1955). 
si c'était indifférent. En revanche, avec le symposion public, l'accent est mis sur le «boire ensemble » d'une communauté politique. Le vin nouveau est inauguré par un symposion public, la matrice de tous les symposia. Le vin nouveau débute par une beuverie publique, la cité indique le sens du « boire ensemble ", un sens éminemment politique ${ }^{56}$. La cité, en tant que corps politique, accueille le don de Dionysos et le partage entre ses membres pour éprouver le plaisir du vin. La communauté ne s'isole pas dans une salle de dimension restreinte de façon à n'accueillir qu'un petit cercle privé de buveurs, mais s'assemble de façon publique, au sens politique de ce terme. La cité régit le « boire ensemble ».

L'ouverture des jarres ne clôture pas la fête, elle l'ouvre au contraire et le vin est libéré. La fin de l'isolement du vin se marque par un double mélange du vin, selon Phanodème, le premier pour Dionysos et le second pour les Athéniens, terme qui désigne sans équivoque le corps politique d'Athènes. En procédant au mélange du vin offert au dieu, les Athéniens effacent la distance qui les sépare du vin enfermé dans la jarre et de Dionysos. À Dionysos, le même vin qu'aux Athéniens. D’une autre manière, ils effacent la distance qui les sépare de Dionysos lorsqu'ils l'honoreront dans les symposia privés avec du vin pur, en buvant eux-mêmes un peu de vin pur. Le symposion public est à la fois la traduction rituelle d'une situation particulière, un « entre-deux-temps » mais aussi le premier symposion car, à cette occasion, les Athéniens boivent le vin nouveau tous ensemble avec Dionysos lui-même. La consommation du vin mélangé est le second versant de la Pitboigia, le premier étant l'ouverture des jarres.

La Pithoigia prend tout son sens avec le symposion public qui succède à l'ouverture des jarres. Une fête poliade fait de chaque citoyen un buveur. La cité fixe les modalités d'une pratique, boire le vin. Il est bu mélangé et tous le boivent ensemble. L'horizon de la Pithoigia est la consommation du vin parce qu'il livre l'accès aux plaisirs que seule l'ivresse délivre. Par cette fête, la cité signifie que le vin et ses plaisirs relèvent des affaires communes ${ }^{57}$. Ni gardienne des plaisirs, ni régente d'un ordre moral, la cité place sous son égide le vin et l'ivresse, en définit la portée mais, au-delà, c'est l'affaire de chacun ${ }^{58}$. Les symposia et leurs plaisirs sont fondés sur le socle politicoreligieux de la cité.

La cité se donne à elle-même un symposion où chaque citoyen n'est enfermé ni dans son individualité ni dans l'appartenance à un groupe restreint. La cité assemblée au sanctuaire du Marais se transforme en une cité de

56 Une inscription de Thasos fait connaître un bâtiment exceptionnel, le symposion; H. DuchÊNe, La stèle du Port. Foutlles du port I. Recberches sur une nouvelle inscription thasienne, Athènes-Paris, 1992, p. 94-95, 98-99.

57 Plut., Propos de table, II, 10 (Mor, 644c).

58 P. Schmitt-Pantel, Rites cultuels et rituel social : à propos des manières de boire le vin dans les cités grecques, in O. Murray, M. Tecusan (éds), In vino Veritas, Londres, 1995, p. 93-104 


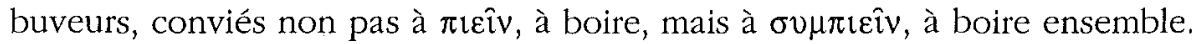
Le repas de viande sacrificielle est fondé sur une égalité arithmétique. Au vin, l'égalité est d'une autre nature et elle n'en est pas moins politique. Ce n'est plus un partage mais c'est chacun comme il veut ${ }^{59}$.

\section{Les Choes}

La deuxième journée des Anthestéries, les Choes, a donné lieu à des développements savants innombrables mais, comme le remarque W. Burkert, tous transforment le concours en un divertissement et donc en une chose simple qui ne requiert pas d'autre explication ${ }^{60}$. La journée des Cboes est marquée par deux cérémonies : le concours des cruches et le mariage sacré. Le Roi préside le concours alors que la Reine s'unit à Dionysos. La Reine et le Roi se répartissent les tâches sacrées dans deux bâtiments civiques, le Thesmothéteion et le Boucoléion. Les rites qui s'y déroulent jouent sur leur confrontation et leur articulation en une même journée. D'un côté, le roi et les citoyens se livrent à un contre-symposion pas réjouissant, le contraire de la journée précédente. D'un autre côté, Dionysos s'unit à la Reine. Par cette union, Dionysos est vraiment dans la cité, du côté féminin.

\subsection{Le concours des Cboes}

Dans les Acbarniens d'Aristophane, un héraut appelle à la célébration de la fête: «Oyez, peuples. Selon l'usage de vos pères, célébrez les Conges en buvant au son de la trompette. Celui qui aura vidé le sien le tout premier, recevra une outre, l'outre de Ctésiphon ${ }^{61}$. Dès l'annonce du héraut, Dicéopolis active son monde à la préparation de son panier ${ }^{62}$. Aristophane souligne les traits du caractère de Dicéopolis : moins une caricature psychologique qu'un portrait du buveur le jour des Choes. Dicéopolis est dépeint en accapareur de biens de toutes sortes. Sa trêve le rend prospère quand la cité manque de tout. Il refuse de vendre à Lamachos des victuailles et il précise que tout cela est pour lui. Ensuite les deux demi-chœurs soulignent l'opulence de Dicéopolis et l'envient. Dicéopolis refuse à un pauvre laboureur ne serait-ce qu'une goutte de la trêve, il se défend d'être un médecin public, pas supplémentaire par lequel il se sépare de la cité. Avec le jeune marié, il se conduira de la même façon. Toute personne ayant un rapport direct avec la marche de la cité est son ennemi ${ }^{63}$. Il se comporte autrement quand il entend

59 Cf. supra, n. 48.

60 Burkert, Homo necans (n. 21), p. 161; Jeanmaire, op. cit. (n. 15), p. 48; Farnell, op. cit. (n. 1), p. 215-216; Parke, op. cit. (n. 30), p. 116. Cl. Calame, Thésée et l'imaginaire athénien, Lausanne, 1990, p. 334; Daraki, op. cit. (n. 25), p. 80.

61 Aristoph., Ach., 1000-1002 (trad. H. Van Daele, Paris, 1926 [CUF]).

62 Ibid., 1003-1007.

63 Ibid., 1018-1056. 
la doléance de la mariée, une femme qui ne peut rien contre la guerre; elle aura donc droit à sa générosité ${ }^{64}$.

A travers Lamachos, Aristophane se moque de Dicéopolis en faisant ressortir le caractère dérisoire de sa fanfaronnade par un parallèle entre leurs combats à livrer. Lamachos va à la rencontre de pillards béotiens et Dicéopolis va combattre d'autres buveurs. Un soldat qui part à la guerre et un banqueteur qui s'en va concourir aux Choes sont sur le même plan et le concours des Choes est chargé de la misère de cette longue guerre. Après les combats, ce n'est pas le guerrier trop peu valeureux - il trébuche en sautant un fossé - qui est célébré, mais un fêtard ivre, en érection et soutenu par des courtisanes, fêté comme le héros victorieux d'un véritable combat. La fin de la pièce joue sur la confrontation, la comparaison des malheurs de la cité et du bonheur d'un individu isolé dans sa cité. La jouissance asociale est placée sur le même plan que l'impuissance de la cité à gagner la paix. Dicéopolis incarne le héros solitaire qu'est le buveur victorieux des Cboes, et Lamachos la cité belliqueuse, aveuglée par ses certitudes. Aristophane fait le procès de l'un et de l'autre ${ }^{65}$.

Le concours des Choes ne se réduit pas à la solitude du buveur mais s'enracine dans un mythe qui lui confère une dimension plus profonde qui met en jeu la cité elle-même. Euripide, dans Ipbigénie en Tauride, donne à Oreste la parole pour expliquer l'origine de la fête des Choes. Oreste raconte que : « Nul ne voulut d'abord me recevoir chez lui, comme haï des dieux. Mais quelques-uns, prenant pitié de moi, m'offrirent une table chez eux. J'étais assis tout seul; on s'arrangea pour me recevoir en silence, et je goûtais, à part, les mets et les boissons, ${ }^{66}$

Les Athéniens ne dérogent pas au devoir d'hospitalité mais l'adaptent aux circonstances. Oreste est enfermé dans sa solitude et le silence des banqueteurs l'entoure. La parole au banquet ne circule plus. Les liens entre les banqueteurs se sont évanouis et ils ne constituent plus une société mais une juxtaposition d'individus. Il n'est plus question que de $\pi$ leîv, de boire, mais en aucune manière de $\sigma v \mu \pi \imath \hat{\imath} v$, de boire ensemble. Cette forme de réunion était perçue comme la négation même du symposion ${ }^{67}$. En plus du silence imposé aux convives, le vin n'est pas tiré d'un cratère commun ${ }^{68}$, de sorte

64

Ibid, 1057-1068

Ibid., 1190-1234.

66 Eur., Iph. en T., 947-952.

67 Puut, Propos de table, II, 10, 643 A; Hagias énumère le manger et le boire pour le plaisir puis le boire ensemble et le manger ensemble, comme si, pour le plaisir égoïste, le manger se nommait en premier tandis que, pour le commun, le boire passait devant le manger. Chaque convive avait reçu une mesure égale de vin et la buvait en silence.

68 Scholie à Aristoph., Ach., 961 Wilson (Groningen, 1975); scholie à Aristoph., Cav., 95 Jones (Groningen, 1969); Souda, s.v. Xóç. 
que chacun des convives est assuré de ne pas boire le même vin qu'Oreste ${ }^{69}$. Les Athéniens ont institué une fête en mémoire des malheurs d'Oreste. Celuici, cependant, n'arrive pas un jour ordinaire à Athènes mais un jour de fête publique :

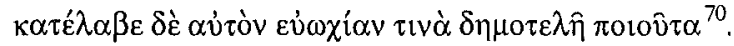

Il (Oreste) le (Pandion) trouva célébrant une certaine fête publique.

En raison de l'état de souillure criminelle d'Oreste, une fête publique est transformée en un rite où chacun boit en silence un vin différent de celui de son voisin. En souvenir des malheurs d'Oreste, les Athéniens accentuent l'inversion. À l'amitié ils substituent l'agôn, la compétition, non pas celle qui oppose des cités aux jeux panhelléniques ou des artistes dans un festival dramatique, mais celle entre les citoyens de la cité. La confrontation s'est insinuée entre les citoyens quand aurait dû prédominer la philia. Ce n'est pas une discussion avec des arguments qui s'opposent, s'annulent et triomphent dans une joute où s'entremêlent le plaisir de parler ensemble et le souci du bien commun. L'aspect agonistique existe au banquet privé et dans le débat public mais d'une manière qui entretient la dynamique de la réunion. Ici, l'intérêt individuel l'emporte. À l'origine, il était motivé par la peur religieuse du contact avec un meurtrier. Dans la perpétuation du souvenir des malheurs d'Oreste, la crainte de la souillure cède le pas au plaisir de triompher des autres. Le concours provoque une fracture entre les citoyens. En outre, le vainqueur s'individualise en opposition au reste des citoyens.

Oreste fut accueilli dans le Thesmotbéteion ${ }^{71}$, là où siégeaient les thesmothètes, les premiers magistrats annuels, qui avaient la charge de « rédiger et de publier les décisions ayant force de loi et de les conserver pour le jugement des conflits ${ }^{72}$. Les thesmothètes instruisaient les procès et introduisaient les accusations devant les tribunaux ${ }^{73}$. La fête primitive était placée sous les auspices des hautes et anciennes instances judiciaires de la cité. Oreste venait à Athènes pour être jugé devant un tribunal. Athènes l'accueille et lui reconnaît une place.

Le déroulement de la fête publique est modifié pour répondre à la présence d'Oreste, ni exclu ni intégré parce que la communauté est comme momentanément suspendue par la présence de la souillure. L'intégration et l'exclusion sont impensables. L'issue réside dans la mise entre parenthèses

69 Aristophane accentue cet usage en faisant apporter à Dicéopolis son propre vin dans son cbous pour le concours des Cboes et en lui faisant ingurgiter du vin pur.

${ }^{70}$ Scholie Aristoph., Cav., 95.

71 Plut., Propos de table, I, 1 (613b). P.J. Rhodes, A Commentary on the Athenaion

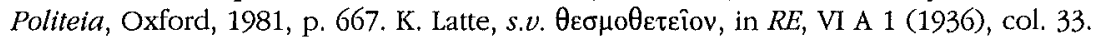

72 Aristote, Constitution d'Athènes, III, 4-5 (trad. G. Mathieu et B. Haussoullier, Paris, $1922[$ [CUF]).

73 Ibid., LIX. 
pour un temps de ce qui fait qu'une communauté existe entre ses membres et que les liens d'attachement mutuel s'expriment par des pratiques qui donnent à vivre ce plaisir d'être ensemble ${ }^{74}$. La cité expérimente la dissolution du sentiment communautaire. Un autre, venu de l'extérieur, donne l'impulsion nécessaire pour connaître cette situation extrême. Quand l'autre prend la triple forme de l'étranger, du suppliant et du meurtrier, la cité est questionnée radicalement, les Athéniens se dispersent au banquet. La parade collective adoptée est l'évitement de toute relation qui pourrait mettre en contact avec un autre. Se protéger déclenche au sein du banquet le surgissement d'un comportement individualiste. Chacun s'isole en son privé.

L'anti-symposion manifeste la fragilité du lien enre les individus et sa réversibilité. Il est moins affaire de définition de la citoyenneté, avec les barrières et les règles que la cité élève et édicte, que de pbilia. Ce lien déborde la citoyenneté, il est surtout d'une autre nature, un sentiment et une volonté ${ }^{75}$. Ces valeurs peuvent vaciller et se métamorphoser en leur contraire, non que la citoyenneté soit subitement plus ouverte ou plus restrictive, mais parce que la communauté est confrontée à une menace et que la seule réponse qu'elle sait improviser est la dissolution du lien social. La citoyenneté, elle, subsiste, mais que vaut-elle quand son ressort disparaît? Que valent des droits et des devoirs quand le plaisir d'être ensemble est dépassé par le souci de soi ? Seule subsiste une collection amorphe de citoyens sans âmes qui peuvent $\pi \imath \varepsilon \hat{\imath} v$, mais sûrement pas $\sigma v \mu \pi \imath \varepsilon \hat{v}$. Parce que la philia n'est ni naturelle ni innée ${ }^{76}$, la menace du morcellement social plane à l'assemblée comme au symposion sans que la stasis, la discorde, menace la paix civile. Les Grecs, inventeurs de la politique, n'auraient pas, selon Platon, inventé la philia. Les dieux durent s'en mêler parce que, sinon, les hommes s'entredéchireraient encore $^{77}$. La pbilia combine désir et plaisir d'être ensemble. Autrement, on ne comprendrait pas pourquoi cela s'est produit au cours d'une fête publique consacrée à Dionysos, les Anthestéries.

74 O. Murray, Histories of Pleasure, in Murray - Tecusan, op. cit. (n. 58), p. 3-16.

75 La communauté n'est pas seulement une affaire de droit, c'est avant tout un « vivre ensemble " confronté à la réalité, aux peines et aux joies, aux souvenirs et aux desseins partagés, discutés. Le socle du lien inter-individuel se constituerait du désir d'éprouver le plaisir d'être ensemble et de satisfaire ce que les Athéniens ont pensé être leur plaisir, un plaisir adéquat à l'idée qu'ils se faisaient de leur nature.

76 Aristote, Pol., 1262 b 7, 1263 a 30; Éthique à Nic., 1161 a 10 sq, 1167 b 2 sq; EscH., Eum., 985. H. ARENDT, Vies politiques, traduit de l'anglais et de l'allemand par E. Adda, J. Bontemps, B. Cassin, D. Don, Paris, 1974, p. 34-35. B. CAssin, De l'organisme au piquenique, in B. CAssin (textes réunis par), Nos Grecs et leurs Modemes. Les stratégies contemporaines d'appropriation de l'antiquité, Paris, 1992, p. 137-139. Chr. Meier, La naissance du politique, Paris, 1995 [or. all. 1980], p. 148-149. La citoyenneté ne détermine pas des comportements et ne procure pas davantage une âme, elle ne fait qu'entériner l'existence de ce sentiment, la pbilia politique, son envergure et surtout ses limites qui s'appellent égoïsme, individualisme ou manque d'imagination.

77 Platon, Prot., 322a-d. B. Cassin, L'effet sopbistique, Paris, 1995, p. 299 et n. 6. 
Le concours des Choes entretient la mémoire des malheurs d'Oreste mais il pérennise aussi l'attention au sens communautaire, une donnée sensible aux pressions individualistes à l'intérieur de la cité, un lien fragile, soluble, réversible. Avec Dionysos, la Pithoigia célèbre le vin nouveau et les plaisirs de l'ivresse partagés en commun. Le lendemain, il fait sentir à la cité que le vin n'est pas un bouclier pour la communauté, il devient l'agent de sa fragmentation. Dionysos ne se manifeste pas explicitement au concours qu'aucun dieu ne patronne mais seulement la cité. Les sanctuaires sont fermés, les couronnes des buveurs ne sont pas déposées dans les lieux sacrés habituels ${ }^{78}$. Les dieux s'isolent moins dans leurs temples que la cité ne se défait dans la compétition des buveurs. Le roi Démophon avait ordonné que les lieux sacrés soient fermés en raison de l'arrivée d'Oreste souillé du matricide. Le souvenir d'Oreste et de sa souillure est perpétué par la répétition rituelle de la décision du roi. Un rite n'épuise pas sa signification dans le seul attachement et la seule fidélité au passé lointain. Un ancrage significatif dans le présent est nécessaire. Il est assuré par la liaison entre le mythe étiologique du concours des Choes et la fête publique célébrée quand Oreste arrive. Le parallèle ne s'établit pas dans la seule répétition de gestes mais il englobe une atmosphère religieuse identique. Le jour des Cboes est néfaste ${ }^{79}$. La malédiction ne résulte pas du seul Oreste, elle s'attache également au concours rituel des Choes qui éclate la communauté des buveurs et déclenche l'éloignement des dieux de la cité. $\mathrm{Ni}$ associés ni destinataires de la fête, la cité ne les célèbre pas et ne se célèbre pas à travers le culte. Les sanctuaires sont donc fermés, sauf un, celui de Dionysos au Marais.

Au concours des Choes, chaque buveur est placé devant sa cruche de vin et, au signal de la trompette, chacun s'empare de son vase pour l'ingurgiter au plus vite. Quand l'un des buveurs signale que sa cruche est vide en la brandissant, les autres buveurs arrêtent de boire. D'un côté, le vainqueur avec une cruche vide et d'un autre, le reste des participants avec un reste de vin dans la cruche. L'opposition entre Oreste et les Athéniens est reconstituée. Ils ont bu séparément, mais à la fin le vainqueur, par sa victoire, est distingué des autres concurrents et séparé d'eux par le fait qu'il n'a plus de vin dans son vase alors qu'il en reste dans tous les autres vases. La position du vainqueur est analogue à celle d'Oreste, tous les deux boivent avec les autres, mais tout les distingue de leurs voisins. Pour le premier, c'est la rapidité à boire et pour le second, une souillure. Le vainqueur est certes un $\pi$ ó $\rceil$ s, un buveur, ce qu'était Oreste, mais pas un $\sigma v \mu \pi$ ó $\eta$ ऽ. Le concours inverse la pratique sympotique, mais il faut que tôt ou tard les choses soient redressées. Le règlement de Démophon stipule que les buveurs portent leur couronne posée autour de leur vase jusqu'au sanctuaire de Dionysos au Marais, la remettent à la prêtresse et offrent à Dionysos le vin restant dans leur chous. Dans le sanctuaire au Marais, tous les buveurs sont en mesure d'accomplir le

78 Phanodeme, FGrHist, 325 F 11 Jacoby = Athénée, $\mathrm{X}, 470 \mathrm{c}$.

79 Photius, s.v. $\mu 1 \alpha \rho \dot{\alpha} \eta \dot{\eta} \mu \varepsilon^{p} \alpha$. 
dernier rite prescrit sauf un, le vainqueur, pour la simple raison que son vase est vide, vidé même de la part de Dionysos. Le vainqueur ne trouve pas sa place dans la libation finale, tout comme Oreste est exclu des libations et des sanctuaires.

Les autres buveurs se retrouvent dans le sanctuaire et se livrent, ensemble, au même geste de la libation à Dionysos. Elle aurait dû précéder la consommation du vin mais, en lieu et place d'une libation, c'est le son de la trompette qui retentit. La consommation précipitée trahit les bons usages du vin. Une fois le premier chous vidé, il demeure des buveurs à qui reste une fraction de leur conge. Le fond du cbous les réunit au Limnaion, le seul sanctuaire ouvert, et ils renouent avec Dionysos. Le concours n'est pas la manière convenable de boire le vin et la parenthèse du désordre institué par le concours se referme. La libation du vin restant est un acte d'allégeance à Dionysos, une manière de rétablir le dieu à sa place centrale et de ramener les buveurs à la sociabilité dont le concours les a éloignés. La communauté des buveurs se reconstitue sous l'égide de Dionysos.

Le concours est le degré zéro de la cité des buveurs. Le vin ingurgité dénote une société qui malmène ses bases communautaires en rejouant une fête qu'elle donnait quand Oreste est arrivé ${ }^{80}$, le temps de surmonter la crainte d'une souillure par le refus des pratiques conviviales. Tout se joue comme un parcours qui débute avec la Pithoigia et le symposion public au Limnaion, enchaîne avec un détour par le Thesmotbéteion et s'achève par un retour au Limnaion pour y rétablir le lien entre les buveurs et Dionysos, et entre les buveurs eux-mêmes qui renouent avec la socialité.

\subsection{Le mariage sacré}

Le jour des Choes, un autre rite, le mariage sacré ${ }^{81}$, se construit dans un rapport complexe au Limnaion. Le concours des Choes se déroule au Thesmothéteion et trouve sa conclusion au Limnaion; inversement, le mariage sacré débute au Limnaion et s'accomplit au Boucoléion. Ces deux rituels partagent un autre trait mais de signe inverse : le concours est présidé par l'archonte-roi tandis que, dans le mariage sacré, son épouse, la Basilinna,

80 Élien, fr. 76 Domingo-Fourasté [Teubner, 1994], donne une curieuse origine au concours des Choes. Il raconte que des Étoliens avaient apporté aux Athéniens le vin que ces derniers ne connaissaient pas, ces derniers le burent avec plaisir, mais croyant avoir été empoisonnés ils tuèrent les Étoliens. Des malheurs s'ensuivent et l'oracle ordonne d'apporter aux Étoliens injustement tués des choes et de célébrer une fête appelée Choes. Dans ce récit, il faut voir une nouvelle page de l'histoire des relations entre les Étoliens et les Athéniens autour du vin. Pour une lecture très élaborée, voir W.A. Borgeaud, Le vigneron diluvial et le chasseur auroral, in $R B P b, 1$ (1972), p. 30-43.

81 A. Avagianou, Sacred Marriage in the Rituals of Greek Religion, Berne, 1991, p. 177197. 
tient avec Dionysos le rôle de premier plan. Dans le mariage sacré ${ }^{82}$, «Dionysos se met lui-même dans la position du roi... revendique la reine, quand il vient.... Cette visite montre vraiment Dionysos comme le dieu qui vient ${ }^{83}$. La réponse que W. Otto donne à la question du mariage sacré est lumineuse. Elle met l'accent sur la substitution qui s'opère entre l'archonteroi et Dionysos auprès de la Basilinna, mais également sur le caractère épiphanique du dieu. La réponse de W. Otto ne se referme pas sur un registre de signification comme le sacrifice, le mariage et la mort, voire la fertilité. Le mariage sacré devait être articulé à une grande cérémonie publique préparatoire qui soulignait l'importance que la cité accordait « au dieu qui vient » et qui s'installe à la place de l'archonte-roi auprès de son épouse $e^{84}$.

La cité, devenue démocratique, s'était entourée de précautions en ce temps de révolution. Elle conservait la royauté et.la transformait en magistrature annuelle ${ }^{85}$. La reine était un maillon essentiel de la vie politico-religieuse de la cité ${ }^{86}$. Une loi définissait les qualités exigées de la Reine : Athénienne et vierge au mariage. Elle comportait en outre l'obligation de suivre scrupuleusement les anciens rites gravés sur une stèle placée dans le Limnaion. Autour de cette lol se bâtit une histoire d'Athènes qui passe par la Basilinna. Cette histoire se condense dans deux rites : épouser Dionysos et accomplir les sacrifices. La Basilinna n'est ni un accessoire ni une survivance dans la vie politico-religieuse d'Athènes. La loi du Limnaion hésite entre le secret et la publicité, mais elle ne peut déroger au principe d'exposition en un lieu accessible à tous. La loi gravée est une «écriture publique », elle doit être

82 Sur deux vases, quelques auteurs ont voulu voir la représentation du mariage sacré. Le premier vase est un cratère en calice AFR de Tarquinia RC 4197; $A R V^{2}, 1057 / 96$. Le second vase est encore moins probant; il s'agit d'un cratère AFR de Syracuse, 23508; $A R V^{2}, 613 / 6$; Voir A. Lezzi-HAFTER, Anthesterien und Hieros Gamos. Ein Choen bilder des Methyse Malers, in J. Christiansen, T. Melander (éds), Proceedings of the 3rd Symposium on Ancient Greek and Related Pottery, Copenhague, 1988, p. 325 sq.; O. GruppE, Griecbiscbe Mythologie und Religionsgeschichte, Munich, 1906, vol. II, p. 965; Farnel, op. cit. (n. 1), p. 217; Deubner, op. cit. (n. 46), p. 100; L. Gernet, Antbropologie de la Grèce antique, Paris, 1976, p. 124; Jeanmaire, op. cit. (n. 15), p. 51-52; E. Simon, Festivals of Attica, Madison, 1983, p. 96-97; BURKERT, Homo necans (n. 21), p. 170-172; DARAKI, op. cit. (n. 25), p. 78, 81; Calame, op. cit. (n. 60), p. 334; Avagianou, op. cit. (n. 81), p. 181-192.

83 Otto, Dionysos (n. 10), p. 91-92.

84 Ibid., p. 91.

85 DÉm., Contre Nééra, 75.

86 Ibid., 73 : «Cette femme a donc célébré les sacrifices secrets au nom de la cité. Elle a vu ce qu'elle n'avait pas le droit de voir en tant qu'étrangère. Une femme comme elle a pénétré là où ne pénètre personne d'un si grand nombre d'Athéniens, sinon la femme du roi. Elle a reçu le serment des prêtresses qui assistent la Reine dans les cérémonies religieuses. Elle a été donnée en mariage à Dionysos. Elle a accompli, au nom de la cité, les rites traditionnels à l'égard des Dieux, rites nombreux, sacro-saints et mystérieux » (trad. L. Gernet, Paris, 1960 [CUF]]. L'orateur parle ici de Nééra dans la fonction de Basilinna. 
visible et lisible par tous ${ }^{87}$. L'ouverture limitée à une seule journée dans l'année et les caractères à demi effacés ne facilitaient pas la diffusion de la lettre de la $\operatorname{loi}^{88}$. Cependant, le principe de publicité était sauf et la stèle « vaut en place du politique absent ${ }^{89}$. Par la loi et la stèle gravée, la cité est présente et dicte à la Basilinna les qualités à rencontrer et les obligations rituelles à remplir.

Auprès de la stèle et de l'autel, la Basilinna fait prêter serment aux Gerarai, prêtresses qui le prononcent sur les corbeilles avant d'accomplir les sacrifices au Limnaion ${ }^{90}$. Le serment, sous l'autorité de l'épouse du Roi, constitue une véritable entrée en fonction des quatorze diaconesses et ouvre leur année de prêtrise au service de Dionysos. La Reine dirige et surtout enclenche le déroulement des rituels. Le Basileus a quitté sa demeure, il préside le concours et évite le contact avec les choses et les lieux sacrés. Son épouse tient entre ses mains le pouvoir religieux dans la cité, au Limnaion, le seul sanctuaire ouvert ce jour-là à Athènes.

Au concours, Dionysos ne se manifeste guère. La cité masculine s'est mise en congé de tout contact, mais surtout elle est en congé de Dionysos, elle ne renouera avec lui qu'une fois le concours terminé. A l'inverse, la Basilinna, en sa position clé au Limnaion, accueille Dionysos. À l'exception du serment et du mariage sacré, les autres obligations cultuelles de la Reine s'accomplissent sous le sceau du secret. Leur succession détermine une solidarité, une unité dionysiaque explicite. Près du Prytanée, au cour politique de la cité, le mariage se déroulait au Boucoléion ${ }^{91}$, la demeure de l'archonte-roi à haute époque. La Basilinna et Dionysos contractaient là un mariage ${ }^{92}$. La Basilinna est mariée légitimement deux fois, une première avec le Roi et une seconde avec Dionysos qui se marie chaque année avec une nouvelle épouse. Chaque année, une Athénienne épouse le dieu dans une fête qui engage la cité à

87 M. Dettenne, L'espace de la publicité : ses opérateurs intellectuels dans la cité, in M. Detrenne (éd.), Les savoirs de l'écriture. En Grèce ancienne, Paris, 1988, p. 39-40.

88 Ibid., p. 42, n. 45.

89 P. Loraux, L'art platonicien d'avoir l'air d'écrire, in Detienne (éd.), op. cit. (n. 87), p. 450 .

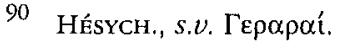

91 Aristote, Constitution d'Atbènes, 3, 5. La localisation du Boucoleion est incertaine parce qu'elle dépend de celle du Prytanée qui est également incertaine. RHodes, op. cit. (n. 71), p. 103-104; J. Travlos, Bildlexikon zur Topograpbie des Antiken Atben, Tübingen, 1971 , p. 2 et 8 , fig. 5 , n. 16.

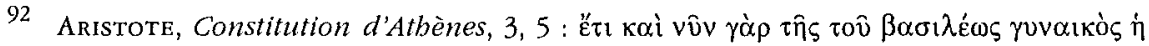

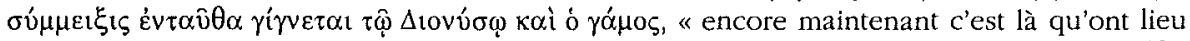
l'union et le mariage de la femme du roi avec Dionysos »; Dém., Contre Nééra, 73, દ̇ $\xi \varepsilon \delta o ́ \theta \eta$

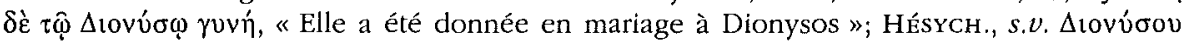

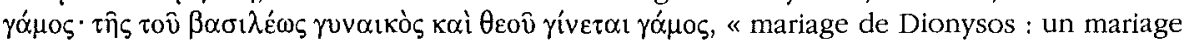
a lieu entre la femme du roi et le dieu "; C. KERÉNYi, Dionysos. Archetypal Images of Indestructible Life, traduit de l'allemand par R. Manheim, Princeton, 1976, p. 309-310; Hamiton, op. cit. (n. 33), p. 56, n.147. 
travers ses plus hautes autorités religieuses, et un couple réveille son passé royal.

Marier Dionysos, remarier la Basilinna arriment Dionysos à Athènes, lui offrent un ancrage, non pas fondé sur le désir érotique ou sur la séduction, mais sur une relation de nature politique, renouvelée chaque année en raison de l'annalité de la magistrature. Entre Basilinna et Gerarai, entre serment et sacrifice, c'est une cité sous l'égide des femmes, des femmes institutionnellement organisées et dont les activités sont codifiées par une loi prise par la cité et gravée sur une stèle placée auprès de l'autel du Limnaion. Des Athéniennes vénérables s'affairent exclusivement au culte de Dionysos. Aucun autre rite religieux ne se déroule dans la cité et les hommes s'adonnent à une compétition du vin. Des femmes incarnent la permanence de la cité, entourant le seul dieu dans la cité, Dionysos.

Les Athéniennes sont, avec Dionysos, seules dans la cité et avec elles Dionysos contracte une alliance en la personne de la Basilinna. La dimension politique de la Basilinna ne se résume pas à se substituer au roi auprès de Dionysos. Par sa médiation les Athéniennes contractent un second mariage. En raison de leur qualité de femme, le mariage est moins l'union de Dionysos avec la cité qu'avec la partie féminine de la cité. Le mariage n'est pas moins politique parce qu'il ne concerne que les seules femmes. S'affichent ainsi et leur autonomie et leur rôle de premier plan dans la présence de Dionysos dans la cité. Leur présence est institutionnelle, la Basilinna est quasiment un magistrat engagé dans l'histoire politico-religieuse de la cité. Du Limnaion au Boucoléion, du centre dionysiaque au centre politique, elles occupent l'espace politico-religieux de la cité.

Au Boucoléion, la Basilinna s'unit à Dionysos dans la demeure du Roi et leur mariage signifie la place étendue et inattendue de la partie prétendument « exclue » de la vie politico-religieuse en cité, les femmes d'Athènes ${ }^{93}$. Le mariage sacré spécifie le lien entre Dionysos et la partie féminine de la cité qui devient médiatrice du vin entre Dionysos et les hommes, familière et interprète qualifiée de Dionysos. Pour donner corps à cette relation, Dionysos recourait au mariage parce qu'il confère à leur union une dimension

93 Sur la place des femmes dans la cité, voir tout particulièrement : Cl. Mossé, La femme dans la Grèce antique, Paris, 1983, p. 89-90; N. Loraux, "Le nom d'Athénien. Structures imaginaires de la parenté à Athènes ", in Les enfants d'Atbéna, Paris, 1981, p. 119-132,153; C. Patterson, Hai, Attikai: The other Atbenians, in Rescuing Creusa: New Methodological Approaches to Women in Antiquity, a special Issue of Helios, $13 / 2$ (1986), p. 49-57 et en particulier p. 62. N. Loraux, Aspasia, la straniera, l'intellettuale, in N. Loraux (a cura di), Grecia al femminile, Bari, 1993, p. 123-1554; S. Georgoudi, Lisimaca, la sacerdotessa, ibid., p. 157-196. M. Detienne, « La force des femmes », in G. Sissa et M. Detienne, La vie quotidienne des dieux grecs, Paris, 1989, p. 238-252. R. Osborne, Women and Sacrifice in Classical Greece, in CQ, 43 (1996), p. 392-405, en particulier p. 404 où l'auteur délimite abruptement la religion, la vie quotidienne et la vie politique; sur ces points voir J.-P. VERNANT, « Religion grecque, religions antiques », in J.-P. VERNANT, Religions, Histoires, raisons, Paris, 1979, p 11. 
officielle. Par le mariage, une femme devenait véritablement une femme, une «Athénienne ${ }^{94}$. Le mariage avec la Basilinna obéit tant au calendrier politique de la cité qu'à celui de Dionysos et de son vin. Alter ego d'un magistrat, une femme représente non pas Athènes en son unité idéologique produite par le discours politique masculin, mais la cité qui prend en compte la différence des sexes et assigne à chacun une position spécifique par rapport à Dionysos.

Le concours des Choes et le mariage sacré font sens dans leur confrontation et se répondent pour faire de Dionysos un pilier de la cité avec la Basilinna et les Athéniennes. Dionysos choisit de venir et de revenir à Athènes de ce côté de la cité et de lui confier la recomposition du lien social, avant que le sanctuaire ne ferme pour un an. Dionysos n'est pas seulement un dieu du vin en tant que tel mais le dieu du vin dans sa consommation comme métaphore de la société, de la communauté civique en son souci du bien commun.

\section{Les Chytroi}

Le troisième jour des Anthestéries ${ }^{95}$, appelé Cbytroi, était encore une fête de Dionysos. Les diverses manifestations du dieu ne sont pas univoques ${ }^{96}$, comportement qu'il affectionne ${ }^{97}$. Il reste à reconnaître la présence de Dionysos au dernier jour des Anthestéries au Limnaion ${ }^{98}$.

94 N. Loraux, Les enfants d'Atbéna. Idées atbéniennes sur la citoyenneté et la division des sexes, Paris, 1981, p. 124-127.

95 Harpokration, glosant $\chi u ́ \tau p o i$, rapporte que, selon Philochore, les Cbytroi se déroulaient le treize d'Anthestérion. Callimaque semble décomposer les Anthestéries en trois journées consécutives : l'ouverture des jarres, celle de la fête des Cboes et enfin la journée d'Erigoné, la fille d'Icarios. Callim., fr. 178, 1-5 Pfeiffer = Origines, fr. 2 Cahen (Paris, 1922 $[C U F]$ p. 140). Les Anthestéries comme un triduum trouvent confirmation dans un commentaire à Thucydide, $P$. Oxy. VI 853 col. x 15-18, cité par Hamilon, op. cit. (n. 33), p. 43 et 166.

96 Rhodes, op. cit. (n. 71), p. 195-196; HARrison, Themis (n. 7), p. 292-293; Kerényi, op. cit. (n. 92), p. 303; Jeanmaire, op. cit. (n. 15), p. 56; Burkert, Greek Religion (n. 18), p. 240241; Homo Necans (n. 21), p. 172-173; DabBab-Trabulsi, op. cit. (n. 24), p. 211; Calame, op. cit. (n. 60), p. 331.

97 M. Detienne, Dionysos à ciel ouvert, Paris, 1986, p. 16-18.

98 L'unique jour d'ouverture du Limnaion est problématique, voir Burkert, Homo Necans (n. 21), p. 159; Hamilton, op. cit. (n. 33), p. 47-48. Le sanctuaire de Dionysos au Marais se décomposait en un téménos avec le péribole qui le ceinturait et un temple à

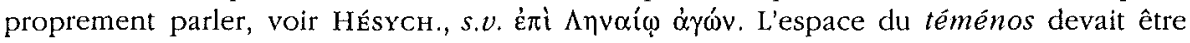
aisément accessible, un scholiaste y mentionnait l'existence d'un bâtiment distinct du temple, scholie Aristoph., Gren., 216 Koster (Groningen, 1967). 


\subsection{Le kômos ivre de la cité}

Les témoignages sur les Cbytroi s'attachent à décrire la panspermie, à mentionner des concours théâtraux ou à indiquer la date de la fête. Un seul renseigne sur cette fête dans son rapport avec Dionysos, un court passage des Grenouilles d'Aristophane 99 . Dionysos, dans la barque de Charon, pousse sur les avirons et les grenouilles donnent la cadence de leurs chants mélodieux. Les grenouilles chantent Dionysos Nyseien et comparent leur

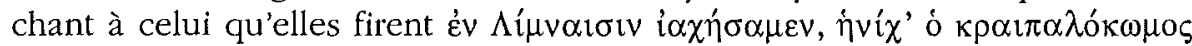

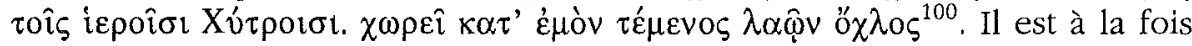
question d'un téménos de Dionysos, d'hymne en son honneur, d'ivresse et de cortège humain $^{101}$. Le chant qui se fait entendre à l'approche du Limnaion est désigné par le terme $\kappa \rho \alpha \imath \pi \alpha \lambda$ ó $\omega \mu$ os qui désigne un hymne chanté $\kappa \alpha \tau \grave{\alpha}$

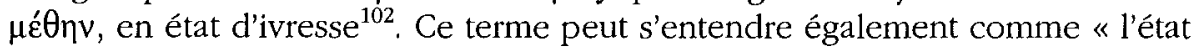
de ceux qui forment un cortège lors des fêtes où l'on s'enivre " ${ }^{103}$. Dans les deux sens, les chanteurs sont en fête et passablement imbibés de vin. Voilà qui éloigne de l'atmosphère lourde créée par les âmes qui volent en tous sens dans Athènes et qui seront bientôt chassées ${ }^{104}$. L'hommage aux morts ne résume pas toute la journée des chytroi et rien n'indique qu'il est incompatible avec une joyeuse atmosphère.

Le terme $\tau \varepsilon ́ \mu \varepsilon v o \varsigma$ désigne une portion d'espace délimité et consacré à une divinité. Cet espace peut contenir un ou plusieurs monuments cultuels mais ne se confond pas avec eux ni ne les implique obligatoirement. Une portion de territoire est découpée et séparée de l'espace profane environnant ${ }^{105}$. Le $\tau \varepsilon ́ \mu \varepsilon v o s$ du Limnaion était ceint d'un long mur qui définissait un vaste espace consacré au Dionysos du Marais ${ }^{106}$. Vers ce sanctuaire, la foule se presse en une vague humaine ivre. Elle ne ressemble pas à la troupe de quelques joyeux noctambules après un symposion bien arrosé ${ }^{107}$. La cité se rend en un cortège

99 ARISTOPH, Gren., 215-219.

100 Ibid., " retentir aux Lymnes, quand, dans l'ivresse du festin, aux saintes Marmites, la foule humaine s'avance en mon pourpris " (trad. H. Van Daele).

101 R.F. MOORTON, Rites of passage in Aristophanes' Frogs, in CJ, 84 (1988-1989), p. 308324.

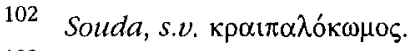

103 VILLARD, op. cit. (n. 51), p. 115.

104 Deubner, op. cit. (n. 46), p. 99-100.

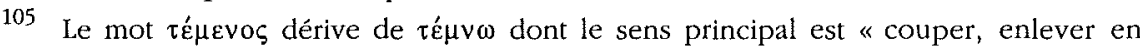
coupant", voir J. CASABONA, Recberches sur le vocabulaire des sacrifices en grec, des origines à la fin de l'époque classique, Aix-en-Provence, 1966, p. 211-219; M. CASEvitz, Temples et sanctuaires, ce qu'apprend la lexicologie, in G. Roux (éd.), Temples et sanctuaires. Sêminaires de recherches de Lyon, 1981/1983, Lyon, 1984, p. 85-87.

106 M. Guarducci, Le Rane di Aristofane e la topografia ateniense, in Studi in Onore di Aristide Colonna, Pérouse, 1982, p. 167-172.

107 Chr. Bron, Le lieu du kômos, in Christiansen - Melander, op. cil. (n. 82), p. 71-79. 
public ivre au sanctuaire ${ }^{108}$. Dans le cortège même la foule s'enivrait, le kômos serait un symposion en marche, en mouvement et autonome d'une autre pratique, le symposion couché. Dans le cortège d'Athéniens le vin devait circuler jusqu'à l'ivresse mais sans salle avec son mobilier approprié, sans épais coussins pour s'accouder la coupe à la main, pour deviser sagement. Dans les rues d'Athènes, le cadre est bouleversé, le refuge et l'intimité du symposion privé sont anéantis par la présence de la foule. Les buveurs sont dans la rue. À nouveau Athènes, comme au premier jour, défile vers le Limnaion. Cette fois le vin nouveau est désacralisé, il irrigue Athènes, au sens propre. La foule revient au Limnaion ivre du vin de Dionysos. Un mouvement pendulaire se développe à partir du Limnaion, trois jours gravitent de manière ininterrompue autour d'un temple fermé les deux-tiers du temps de la fête. Le premier jour, une première vague atteint le Limnaion, elle s'évanouit dans le concours des Choes pour se reconstituer individu par individu dans la libation du reste, mais le lendemain, jour des Chytroi, une vague plus puissante atteint le sanctuaire. En retraçant le balancement imprimé par les rites successifs, le centre de gravité des Anthestéries est restitué, le Limnaion.

Après le symposion public de la Pitboigia, une autre consommation publique du vin est attestée. Les Athéniens renouvellent une pratique éminemment sociale. La cité boit et s'enivre, elle s'éprouve collectivement au révélateur du vin bu ensemble. Le vin devient ici le puissant lien social, pas celui du groupe restreint du symposion, mais le lien entre tous. Ce « boire ensemble » procure l'ivresse collective, il coïncide avec la cité et lui donne une allure grise. Le vin acquiert ici encore plus de poids politique, sa puissance de convivialité se diffuse à toute la cité. L'égalité et l'ivresse se conjuguent à Athènes pour réaliser l'intégration de tous dans le cortège qui se porte au Limnaion.

En marchant vers le sanctuaire de Dionysos, le cortège, par son ouverture, n'abolit pas les catégories mais les transcende en une entité qui se constitue dans le mouvement de sa marche et de son ivresse vers le Limnaion. Les statuts s'éclipsent dans une pratique qu'aucun groupe ne peut annexer. Le symposion ambulant est une pratique poliade au sens où elle appartient à la polis et la dénote, mais une polis « recalibrée » qui ne peut être revendiquée par aucune des minorités qui la constituent, aussi puissante soit-elle d'ordinaire.

Le dernier jour des Anthestéries constitue une réplique au jour médian des Choes. La foule ivre témoigne que la menace de dissolution de la cité reconnue la veille n'est pas seulement surmontée - cela s'était réalisé dans la libation du reste la veille - mais dépassée par une autre pratique du vin, une pratique itinérante. La foule, bigarrée et mouvante, ne ménage guère de possibilité au dialogue, aux conversations intimes. L'attention se porte sur le plaisir de l'ivresse. Le symposion public ne constitue pas un modèle montrant

108 Plut., Mor., 501e (trad. J. Dumortier et J. Defradas, Paris, 1975 [CUF]). 
des limites à dépasser. Les deux formes du «boire-ensemble » développées par les deux jours extrêmes des Anthestéries montrent une complémentarité qui dénonce le caractère asocial du concours. À l'approche du Limnaion, dans l'ébriété, la cité atteint l'unité. Il ne s'agit pas de résorber des différences ou des inégalités mais de réaffirmer une adhésion partagée par tous à une cité telle qu'elle se donne à voir à elle-même ${ }^{109}$. Le vin procure l'énergie fusionnelle et l'espace sympotique se confond avec la rue ${ }^{110}$.

\subsection{Les marmites de bouillie}

Le dernier jour des Anthestéries ne tire pas son nom d'une foule avinée mais du récipient dans lequel était cuisinée une préparation à base de semences variées. D'après Théopompe, l'unique source, les survivants du déluge préparèrent dans des marmites une panspermie, un mélange de graines en général ${ }^{111}$. L'agriculture plus que la vie «au blé » est visée. Elle requiert des produits complexes, levée avec fermentation et cuisson au four tandis que la panspermie est simple mélange bouilli, mieux cuit que le rôti ${ }^{112}$.

Les destinataires de cette préparation varient avec les sources. Selon Didyme $^{113}$, on faisait bouillir une panspermie et on sacrifiait à Dionysos et à Hermès. Théopompe indique que les survivants du Déluge donnèrent le nom de Cbytroi à toute la fête le jour où ils reprirent courage après le Déluge ${ }^{114}$. Ils avaient coutume de ne sacrifier à aucun des Olympiens mais seulement à Hermès Chthonien. Enfin, aucun des prêtres ne devait goûter de la panspermie dans une version ${ }^{115}$, interdiction étendue à toute personne dans une autre version ${ }^{116}$. Ces données font abstraction de Dionysos et cela est vrai des témoignages inspirés de Théopompe, comme si ce rituel n'avait pas de rapport avec les Anthestéries. D'après les témoignages dérivés de Didyme, à la fête des Cboes semble correspondre le sacrifice à Dionysos et à la fête des Cbytroi celui à Hermès, le tout tenant dans une seule journée. Au troisième jour des Anthestéries ou à la fin des Anthestéries ${ }^{117}$, Dionysos paraît expulsé

109 L.E. Rossi, Il simposio greco arcaico e classico come spettacolo a se stesso, in Atti del convegno di studio "Spettacoli conviviali dall'antichità classica alle corti italiane del $400 »$, Viterbe, 1983 , p. 41-50 et surtout p. 46.

110 Ibid, p. 50.

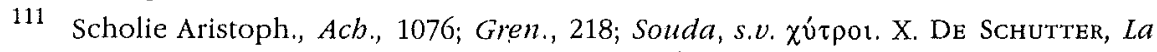
marmite et la panspermie des morts, in Kernos, 9 (1996), p. 333-345.

112 Detienne, Dionysos (n. 97), p. 180-182.

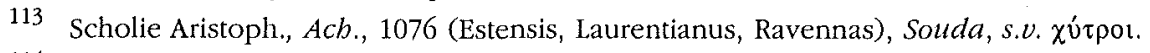

114 Scholie Aristoph., Gren., 218.

115 Ibid.

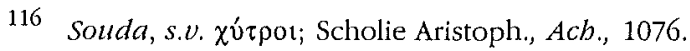

117 Théopompe et les scholiastes qui l'utilisent sont incertains sur le jour où se tenaient les Cbytroi. Une scholie à Aristophane ne donne pas le jour des Cbytroi, scholie Aristoph., Gren., 218. D'autres témoignages indiquent le jour des Choes pour le rite des 
de ses fêtes, sauf à rattacher les rites des Chytroi à l'ensemble du rituel dionysiaque.

Le Dionysos d'Aristophane navigue vers le monde souterrain sur la barque de Charon quand on évoque les Chytroi. Les morts ne sont pas conviés, Dionysos va vers eux. Selon Théopompe, seul Hermès Chthonien est concerné par le sacrifice de ce jour, Dionysos n'est pas cité. Les survivants faisaient cela, selon un scholiaste ${ }^{118}$, parce qu'Hermès avait rapport avec la mort. Cependant, les morts ne sont pas ici les morts en général, mais seulement ceux du déluge. Les Chytroi, dans la version de Théopompe, commémorent un événement par lequel l'humanité avait manqué de disparaître. Les survivants, peu nombreux, honoraient leurs morts en sacrifiant à Hermès Chthonien, conducteur des âmes par les mêmes voies que l'eau à la fin du Déluge avait empruntées ${ }^{119}$. Ils reprenaient courage - en témoignait la préparation de la panspermie - et jetaient les bases d'une nouvelle humanité. En faisant bouillir toutes sortes de semences, les survivants évoquaient le démarrage de la nouvelle humanité confiante en son activité, mais se situant à un stade de développement inférieur par rapport à la vie « au blé moulu ». La panspermie est donc moins tournée vers les morts que vers les survivants qui attendent de leurs semences une alimentation variée. Il ne s'agit pas d'une fête des morts en général ni d'une fête des morts du Déluge en tant que telle, mais d'une humanité en tension entre un passé immédiat destructeur et un avenir en construction, dans un présent tâtonnant ${ }^{120}$.

Selon une version, les prêtres n'ont pas le droit de goûter à la panspermie et selon une autre, personne n'a le droit d'y goûter ${ }^{121}$. L'interdiction faite aux prêtres est une consigne qui s'ajoute à l'interdiction pesant sur les gens du commun, excluant la possibilité d'un privilège sacerdotal. Cela ne constitue pas la panspermie en repas des morts ${ }^{122}$. Elle n'est pas un sacrifice mais un rite sans destinataire qui évoque le moment qui lui a donné naissance. Rien qu'un moment à dépasser qui contient la promesse d'un autre horizon d'humanité à atteindre. Refaire bouillir les semences donnait la mesure du chemin parcouru depuis ces temps lointains en termes de progrès humains. S'abstenir de consommer cette préparation se comprend dans la mesure où elle désigne un stade inférieur d'humanité.

La place de Dionysos demeure problématique. Les Marmites désignent une époque sinistre et dépassée. Sur le même plan, un autre rite peut lui faire

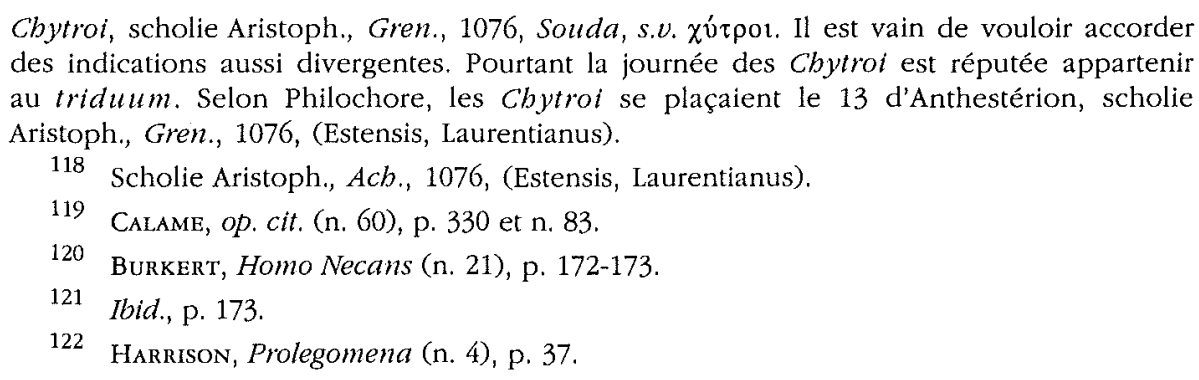


écho, célébrant les morts de la première introduction du vin en Attique par Dionysos, au temps où l'humanité partageait avec les animaux un même breuvage, l'eau.

\subsection{L'Aiôra en souvenir de la mort d'Icarios et d'Érigoné}

Le rattachement de l'Aiôra, ou fête de la balançoire, aux Anthestéries n'est plus guère discuté mais le jour de sa célébration, le deuxième ou le troisième jour, demeure débattu ainsi que l'interprétation à donner de cette fête $^{123}$. Le mythe à l'origine de la fête devrait permettre, davantage que le rite mal connu de la balançoire, de comprendre les enjeux de cette fête et ses liens avec les autres aspects de la dernière journée des Anthestéries.

L'Aiôra se rapporte à la mort d'Icarios et d'Érigoné consécutive à une introduction maladroite de la vigne et du vin en Attique par Dionysos. La fête, la mort du père, de la fille et de la chienne, l'introduction du vin sont autant de maillons d'une chaîne ${ }^{124}$, Dionysos en supervise le déploiement. Chez Icarios, il tente d'introduire la vigne et le vin, et il échoue. Les bergers croyant à un empoisonnement, tuent Icarios. Ensuite, Érigoné se pend et sa chienne se jette dans un puits. Dionysos, furieux de ces morts en série, châtie les Athéniens sévèrement en envoyant une épidémie qui sème la désolation dans la cité. Le châtiment de Dionysos pousse les filles des Athéniens à subir le même sort que celui d'Érigoné, laquelle l'avait souhaité pour ses consœurs $^{125}$. Une épidémie de suicides frappe les jeunes filles nubiles. La Canicule s'était levée et contrariait le développement de la végétation. L'Attique expiait la mort d'Icarios et d'Érigoné doublement parce que c'était la pérennité d'Athènes qui était en jeu. La cité se mourait de perdre ses futures mères et dans l'immédiat, Athènes connaissait la famine. La situation était, à ce moment, aussi dramatique pour Athènes que pour l'humanité du Déluge, mais pour une autre raison, un excès de chaleur. Dans les deux cas, une fête est instituée pour satisfaire les morts, mais également pour pointer du doigt un horizon encore éloigné. La panspermie établissait une articulation entre le passé et un avenir indéterminé, le présent historique; un raisonnement parallèle est possible pour comprendre l'Aiôra. Dans la fête instituée en l'honneur d'Érigoné, il est prescrit de lui offrir les prémices des fruits de la vendange ${ }^{126}$,

Réserver les prémices des vendanges à la victime innocente de l'introduction maladroite du vin découle de la place occupée par les grappes vendangées dans le complexe développé autour du vin. La grappe de raisin se situe à

123 B.C. Dietrich, A rite of swinging during the Antbesteria, in Hermes, 89 (1961), p. 36-50; J. HANI, La fête atbénienne de l'Aiora et le symbolisme de la balançoire, in REG, 91 (1978), p. 107-122.

124 S. Lonsdale, Dance and ritual Play in Greek Religion, Baltimore, 1993, p. 133-136.

125 HYGIN, Astr., II, 5.

126 HYGIN, Fab., 130. 
mi-chemin entre l'absence de la vigne et la présence du vin. Le raisin vendangé n'est qu'un vin en puissance. Ainsi le rituel de l'Aiôra établirait une transition entre le drame d'une introduction manquée du vin et le retour de Dionysos, comme la panspermie faisait le lien entre la menace de disparition de l'humanité et la vie " au blé moulu ». Entre les deux venues de Dionysos, la viticulture se maintiendrait mais sans son prolongement, le vin. De la même manière avec la panspermie des Cbytroi, les hommes reprenaient espoir sans pour autant connaître un état de vie " au blé moulu ». Les deux rituels se répondent comme des remémorations des moments critiques de l'histoire humaine et des répétitions de rites qui ont permis de les conjurer, de lever les barrières sur le chemin du temps présent qui est un aboutissement.

\subsection{Chasser les Kâres pour en finir avec les Anthestéries...}

Les Anthestéries s'ouvrent par la désacralisation du vin nouveau et sont clôturées par une formule qui proclame la fin de la fête, formule qui aurait

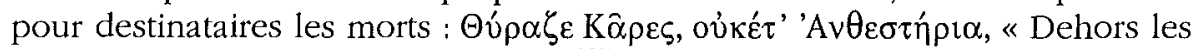
Kâres, les Anthestéries sont finies ${ }^{127}$. Photius dit que les âmes des morts circulaient dans la cité ${ }^{128}$. Ces morts ne se confondent pas avec les morts en général, c'est moins en tant que morts qu'ils étaient associés aux rites de cette journée qu'en tant qu'ayant appartenu à l'humanité disparue dans les eaux du Déluge. Ces morts sont également Icarios, Érigoné mais surtout les vierges d'Attique, toutes morts menaçant de nouveau l'humanité mais plus précisément la cité. Les morts qui sont invoqués tant dans les Chytroi que dans l'Aiôra sont ceux qui incarnèrent soit la menace de disparition de l'humanité soit la menace de disparition de la cité d'Athènes. Dans un cas comme dans l'autre, une fête fut instituée pour commémorer le dépassement de cette menace. En conjurant la menace de disparition, les rites nouveaux ne rétablissaient un ordre identique ni à celui du passé ni à celui de l'époque historique, mais définissaient une période transitoire, un degré inférieur de civilisation auquel les vivants se sentent reliés et dont ils sont débiteurs : les semences précèdent les récoltes comme le raisin précède le vin. Avec ces morts-là, les Athéniens n'en auront jamais fini puisqu'ils constituent le socle de leur propre civilisation.

Les Kariens ne sont pas tous les esclaves, mais des esclaves qui se différencient des autres par une origine géographique spécifique, la Carie en Asie

127 Burkert, Homo Necans (n. 21), p. 165-168, w. Burkert est allé à la fois trop loin dans l'expulsion des morts et dans la place donnée à ses Kariens dans les Anthestéries. S'il a raison de débarrasser les Anthestéries de cette vision funéraire issue des théories religieuses animistes du $x_{x} x^{e}$ siècle, il est excessif de ne pas reconnaitre une présence des morts dans la dernière journée des Anthestéries où il est à la fois question des morts du Déluge et de la première introduction du vin en Attique.

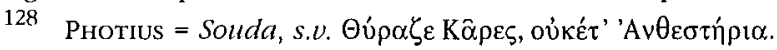


Mineure $^{129}$. Les Athéniens partagent avec eux un territoire, l'Attique, mais aussi le vin des libations. Ils reçoivent de plus les esclaves dans leurs maisons. De plusieurs façons les Kariens se rattachent à l'Attique non pas en raison d'une continuité temporelle mais par une convivialité spatiale à durée limitée, le temps d'une fête. Pour les Athéniens, il ne s'agit ni de revivre le temps de la panspermie et de l'eau pour tout breuvage après le déluge ni d'instituer une sociabilité permanente avec les esclaves. Les Kariens sont comme les substituts ou les équivalents structurels des morts des temps lointains ${ }^{130}$. Ils incarnent cet autre dont on est proche et étranger en même temps; avec lequel un partage est possible et dont la finalité est autant d'afficher le caractère temporaire que la distance à retrouver. Cet autre n'est pas l'étranger lointain, le Karien de Carie, mais celui qui est proche, voire familier. Les esclaves permettent cette courte réunion parce qu'ils sont la partie de la population avec laquelle la cité ne risque pas de se confondre. Dionysos n'est pas une divinité qui intégrerait les esclaves parce que, par nature, il serait un dieu humaniste. La participation des esclaves aux Anthestéries n'est que temporaire et découle de leur voisinage. Les Athéniens instituent une convivialité avec les morts-esclaves précisément à un moment où ce qui est en jeu n'est pas le présent de la cité mais son passé résolu dans l'état actuel de la cité; un état de la cité où la place des esclaves n'est absolument pas problématique, pas davantage que celle des morts.

L'interprétation globale d'une fête aussi complexe que les Anthestéries est hasardeuse surtout quand la documentation est aussi fragmentaire ${ }^{131}$. Cependant l'examen des témoignages montre que les Anthestéries combinent différents scénarios centrés sur la présence du vin et les modes de sa consommation, mais également sur son absence, ou plutôt sur celle de Dionysos. Les Anthestéries sont une grande fête du vin et de la cité réunis par un Dionysos politique, soucieux de sociabilité et d'unité de la cité. Il est prompt à faire ressentir la fragilité des bases mêmes de la sociabilité, prompt à donner une place aux femmes dans la cité précisément quand les hommes se dispersent dans un comportement individualiste. Les Anthestéries sont à la fois des rites inséparables d'un symposion public et d'un cortège ivre de la cité. Les enjeux des trois jours de fêtes se déclinent de manières diverses, chacune politique, selon les états différents du vin que Dionysos livre à la cité. Les Anthestéries constituent le plus important témoignage d'une cité qui

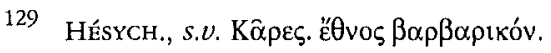

130 Les Kêres, ces petits personnages ailés qui peuvent voleter sur quelques représentations céramiques et qui sur le champ de bataille se précipitent sur le blessé, n'ont aucun rapport avec l'âme du mort qui descend dans l'Hadès pour un long séjour; Voir J. REDFIELD, La tragédie d'Hector, nature et culture dans l'lliade, Paris 1984 [or, angl. 1975], p. $227-230$.

131 Hamilton, op. cit. (n. 33), p. 61-63; H. Hoffmann, Heroic immortality on Athenian vases, in S. Goldhill, R. Osborne (éds), Art and text in ancient Greek culture, Cambridge, 1994, p. 44-49; Calame, op. cit. (n. 60), p. 329-330. 
s'irrigue de vin. La cité institue au cœur même de son existence générale le vin qui coule pendant trois jours sous de multiples formes. La cité se confond avec le vin et se donne en exemple à tous, indiquant la voie à suivre.

Daniel NoEL

Centre Louis Gernet

10, rue Monsieur le Prince

$\mathrm{F}-75005 \mathrm{P}_{\mathrm{ARIS}}$ 